\title{
Evolution of quality culture in an HEl: critical insights from university staff in Bangladesh
}

\author{
Naureen Rahnuma ${ }^{1,2}$
}

Received: 10 April 2019 / Accepted: 25 November 2019 / Published online: 3 January 2020

(C) The Author(s) 2020

\begin{abstract}
This paper evaluates experiences of quality culture as actualized by academic and administrative leaders in a nonprofit, private Bangladeshi university, ensuing the recent implementation of a state-stipulated national quality framework. Based on the data derived from ten interviews integrated with the Quality Assurance Framework document objectives, the purpose of this paper is to gain critical insight on what is working and what might need changing or developing in the future to support quality culture at higher education institutions. The article translates the key themes and elements of the evaluation process into a logic model to show the processes and structures through which the university can support the development of its internal quality culture. It offers a focused pathway for quality assurance activities, crucial in reinforcing and strengthening a culture of quality in Bangladeshi universities. As such, the paper seeks to make a contribution to Bangladesh's higher education by providing a broad, evaluative insight into the preparedness and receptivity of the institutions to integrate sustainability into their teaching and learning as guided by the new quality assurance framework, mindful of the imperatives for quality assurance and enhancement coming mainly from the Western perspective, hence placing its development in the regional, and then global, context.
\end{abstract}

Keywords Quality assurance framework · Quality culture · Enhancement · Higher education $\cdot$ Bangladesh

\section{Introduction}

As the demand for quality education increases in an extremely competitive world, quality assurance (QA) has long been recognized as the key to effective education in

Naureen Rahnuma

n.rahnuma@lancaster.ac.uk; naureen@iub.edu.bd

1 Department of Educational Research, University of Lancaster, Lancaster, UK

2 Department of English and Modern Languages, Independent University, Bangladesh, Dhaka, Bangladesh 
the case of higher education institutions (HEIs) where there is increased mobility of students, faculty, and programs particularly in global networks (Hou et al. 2012; Varonism 2014). Even though the concept of quality emerged in higher education (HE) in the early 1980s "from its more familiar industrial and commercial settings" (Newton 2002, p. 45), it eventually came to be seen as something which could be defined and measured. Quality assurance and enhancement (QAE) of a country's HE is not only key to its social and economic well-being, it is also a determining factor affecting its status at the international level (UNESCO 2005). Indeed, enhancement of quality in HE has become one of the most prominent conceptualizations of internationalization in HE (Maringe 2010). The very term "internationalization" and what it means is frequently contested as being associated with international staff and student recruitment, success in terms of research funding, and international academic and research collaboration that help determine the position of HEIs in global university rankings, usually dictated from the Western perspectives directed toward other regions in the world (Wihlborg and Robson 2018).

However, ensuring that the quality of programs meet local and international standards has become a major challenge in many countries (OECD and World Bank 2007), especially in many South Asian nations. To address this, HE policymaking in a South Asian nation like Bangladesh is currently focused on strengthening QA policies, evolving from relevant national educational legislations and directives to pave the way for the formation of a national accreditation body for Bangladeshi HEIs. Introduced in 2014, Bangladesh's QA mechanisms are still in the process of being fully implemented across every HEI through the establishment of Institutional Quality Assurance Cells (IQACs), guided by the Quality Assurance Unit (QAU) under Bangladesh's University Grants Commission.

\subsection{Higher education in Bangladesh: an overview}

As one of the world's most densely populated countries, Bangladesh is home to more than 162 million people. In the past few years, the country has experienced strong and steady gross domestic product growth rates of above $6 \%$, most of which is generated by the service sector and manufacturing industries. Named as one of the Next Eleven emerging markets by Goldman Sachs, Bangladesh's leadership increasingly view the growing impact of HEIs in knowledge production through research and innovation and recognize the necessity of strengthening its $\mathrm{HE}$ sectors so as to facilitate in transforming and creating a knowledgeable and upskilled workforce that will steer the country forward.

Indeed, the country has experienced a tremendous surge and moved from elite to mass $\mathrm{HE}$ as the total domestic tertiary enrolment over the past decade has surpassed five million students in 2018 (see Table 1). Between 2009 and 2018, the number of private universities grew exponentially from 51 to 103 whereas there was a $30 \%$ increase as the number of colleges increased from 1907 to 2487 particularly in the private sector. By contrast, there was a growth only from 31 to 42 universities in the public sector while a rise from 253 to 673 colleges was recorded between 2009 and 2018.

As of now, Bangladesh's HE system comprises of 46 publicly funded and 103 private universities, a distance-mode Bangladesh Open University, and a large number 
of colleges and tertiary institutions affiliated with the government-owned Bangladesh National University. The largest segment of HE in Bangladesh is comprised of these undergraduate colleges which enrolled 4.28 million in 2018 constituting more than $79 \%$ of total enrollment in tertiary education. This commensurate an increase in the Gross Enrolment Ratio from 10.86 to $20.57 \%$, as estimated by UNESCO Institute of Statistics, in the tertiary education sector in Bangladesh between 2009 and 2018. Owing to an escalating social demand for HE due to this demographic pressure, such tremendous increase in student enrolment and the growth of HEIs (Huisman 1995) over the past decade have made Bangladesh an exemplary phenomenon of massification (Trow 2007; Ahmed 2016) of HE. However, in view of this improved access to HE in achieving "equality of opportunity" (Trow 2007), one of the greatest limitations lies in the lack of transpicuous QAE policies which warrant best teaching and learning practices in Bangladeshi HEIs while maintaining and continually improving its standard. These issues were addressed in the government's National Education Policy (2010), and the establishment of a national accreditation council was endorsed as part of University Grants Commission's Strategic Plan for Higher Education 2006-2026. With financial support from the World Bank (USD 257.11 million), the Higher Education Quality Enhancement Project has been Bangladesh's toolkit to promote academic innovation in universities through a competitive Academic Innovation Fund as well as to enhance global interconnectivity among universities through the development of Bangladesh Research and Education Network while launching a Bangladeshi digital library portal. The establishment of a Quality Assurance Framework (QAF) as part of the effort to further university accountability, nonetheless, remains the major constituent of the project initiative as Bangladesh prepares to meet the estimated tertiary education demand of an additional 700,000 over the next decade (British Council Report 2012).

Prior studies point out dearth of infrastructural facilities and lack of skilled academic staff producing quality research outputs besides issues of profit orientation among many Bangladeshi private HEIs (Ehsan 2008). More attention recently has been drawn toward the provision of more efficient and competitive HE pointing toward a growing focus on using QA as an important mechanism to make Bangladesh more prepared to tackle the global challenges of internationalizing its HE. Therefore, much of the current research literature on Bangladesh's journey toward QA provide insights into the issues, challenges, and its prospects (Islam 2014; Ramirez and Haque 2016; Islam et al. 2017) with a focus on employability of Bangladeshi graduates (Lamagna et al. 2017) and their perception of quality (Akareem and Hossain, 2012). Although a recent study (Parvin 2019) had specifically examined the challenges in QA in Bangladesh's HE through the lens of managerial leadership taking the case of a public university into consideration, further investigation into quality culture (QC) has been recommended to shed light on the organizational environment wherein staff work to realize their specific tasks (EUA 2006) in order to advance QA with a more contextual approach. Given such a context, the aim of this paper is to report findings from an action research (McNiff and Whitehead 2002) that evaluates QC which "stems from a broader cultural perspectives" (Harvey and Stensaker 2008, p. 431) as actualized by administrators and academics in the case of a private Bangladeshi university. Since personal interpretation is also "part of the contested terrain" (Kunda 1992, p. 227) in exploring dimensions of an organization's "shared norms, values, and assumptions" (Schein 1996, p. 229), the paper 
Table 1 Number of HEls and students, 2018

\begin{tabular}{lllll}
\hline & Public & Private & Total institutions & Students (million) \\
\hline Universities & 42 & 103 & 145 & 1.03 \\
Colleges & 116 & 2487 & 2603 & 4.28 \\
Polytechnic & 52 & 387 & 439 & 0.25 \\
Total & 210 & 2977 & 3187 & 5.56 \\
\hline
\end{tabular}

Source: BANBEIS 2018

presents in-depth narrative accounts of both academic and administrative staff. By making an argument for an internal QAF, sans a compliance-only approach, for creating, embedding, and sustaining a culture of quality based on staff insights, the study, guided by a sociocultural perspective, seeks to examine three key research questions:

- What are the reported barriers in the development of QC in HEIs?

- What is the use of QAF in developing a QC in HEIs?

- What measures need to be taken in HEIs to support the development of QC over time?

\subsection{Literature review}

\subsection{Quality assurance in HE: quality and the concept of quality culture in education}

As a relative concept, quality has several dimensions and is conceptualized according to the circumstances in which it is invoked and means different things to different people (Harvey and Green 1993). Every stakeholder in HE, regardless of their roles as students, teaching and non-teaching staff, employers, government and its funding agencies, accreditors, validators, auditors, and assessors, such as, professional bodies, has a different perspective on the success and sustainability of QA which is embedded primarily on QC. Culture, on the other hand, must be understood as a social and socially constructed structure which comprise of durable, layered patterns of cognitive systems, and is embodied in artifacts, embedded in behavior, passed about in interaction, internalized in personalities, and externalized in institutions (Hays 1994). The excerpt (Fig. 1) provides definitions of quality in HE as delineated by Harvey and Green (1993).

Indeed, the privatization of $\mathrm{HE}$ over time has led to the proliferation of different instruments for the evaluation of quality, which influences HEIs on how quality is controlled in their provision of education services (Harvey, 2002; Harvey and Stensaker 2008). Although different in approaches, QA processes in HE are practiced throughout the world with the aim to assure and safeguard academic quality and standards of learning opportunities besides promoting systematic as well as continuous enhancement while ensuring that information about programs are accessible and fit for all purpose. And best practices for QA require clearly defined and transparent code of 
practice on criteria that serve as reference point for evaluations and reports of programs offered by HEIs. Furthermore, university leadership incorporating QA mechanisms must consider "multiplicity of instruments" and "channels of accountability" including (Salmi 2008, p. 7):

the extent to which access is offered evenly to all groups in society (equity), the standards of teaching and research (quality), the degree to which graduates receive an education matching labour market needs (relevance), the contribution of the university to local and/or national economic development (sometimes called the "third mission"), the values imparted by tertiary education institutions (citizenship and nation-building), the manner in which public resources are utilized (internal efficiency) and the financial capacity of the tertiary education system to grow and maintain high standards at the same time (sustainability)

Crucial to the success and sustainability of QA is a positive QC, which is the key ingredient in a successful total quality management program (Seraph and Sebastian 1993; Westbrook 1993), indispensable in achieving the quality goals of any organization. QC has been defined as the pattern of habits, beliefs, and behavior concerning quality (Gryna et al., 2007). Most academics and practitioners who study organizations suggest the concept of culture to be part of a certain environmental context (Hatch and Cunliffe, 2006) and practices that organizations develop around their handling of people (Schein 2004). Culture as such provides rules for behavior within organizations (Yang 2007) and organizational culture comprises of shared beliefs that guide "those most intimately involved in the organization's workings" (Tierney 1988, p. 3) in knowing what could or could not be done with regard to professional practices. While organizational culture is thus deemed to be the key to running a successful organization, it is crucial to investigate the constituents that help construct an organization's culture to gather more clear insight into how organizations function (Schein 1996, p. 229).

The concept of QC has been noted to be synonymous to a complex socialconstructivist phenomenon which is sculpted by organizational context, values (Berings and Grieten 2012), and the development phase of dealing with quality management in which the organization resides (Bollaert 2014). As delineated primarily by the European University Association (EUA), the organizational structural/ managerial and organizational cultural/psychological elements of QC in HE must be linked through elements such as communication, participation, and trust (as in Fig. 2). As such, the QC in any organization is difficult to assess (Bendermacher et al. 2017) as it involves shared, underlying assumptions (Cameron and Freeman 1991) of individuals in the organization. Hence, a QC can be regarded as a specific kind of organizational culture that is influenced by "soft" aspects (e.g., values, beliefs, and commitment) besides "hard" aspects (e.g., quality management, strategies, and processes) (Bendermacher et al. 2017).

While prior research has highlighted barriers for the implementation of quality at the institutional level (Kohoutek et al. 2013; Land and Rattray 2014), changes in organizational culture are increasingly recognized as one of the primary conditions for successful implementation of Total Quality Management (Hildebrandt et al. 1991). In consequence, a number of studies have prioritized QC as a matter of internal institutional quality in HEIs and as a key for continuous improvement, sustainable 


\begin{tabular}{ll}
\hline Quality & Definition \\
\hline Exceptional & $\begin{array}{l}\text { A traditional concept linked to the idea of 'exceltence', usually opera- } \\
\text { tionalised as exceptionally high standards of academic achievement. } \\
\text { Quality is achieved if the standards are surpassed. }\end{array}$ \\
Perfection or & $\begin{array}{l}\text { Focuses on process and sets specifications that it aims to meet. Quality } \\
\text { in this sense is summed up by the interrelated ideas of zero defects and } \\
\text { consistency }\end{array}$ \\
Fitness for purpose & $\begin{array}{l}\text { Judges quality in terms of the extent to which a product or service meets } \\
\text { its stated purpose. The purpose may be customer-defined to meet } \\
\text { requirements or (in education) institution-defined to reflect institutional }\end{array}$ \\
Value for moncy & $\begin{array}{l}\text { Assesses quality in terms of return on investment or expenditure. At the } \\
\text { heart of the value-for- money approach in education is the notion of } \\
\text { accountability. Public services, including education, are expected to be } \\
\text { accountable to the funders. Increasingly, students are also considering } \\
\text { their own investment in higher education in value-for-money terms. } \\
\text { Sees quality as a process of change, which in higher education adds } \\
\text { value to students through their learning experience. Education is not a } \\
\text { service for a customer but an ongoing process of transformation of the } \\
\text { participant. This leads to two notions of transformative quality in } \\
\text { education: enhancing the consumer and empowering the consumer. }\end{array}$
\end{tabular}

Fig. 1 Definitions of quality in HE. Source: Harvey and Green 1993

competitive advantage, and excellence in the context of a knowledge-based society, mostly in European nations (Barbulescu 2015; Adina-Petruța 2014; Greere and Riley 2014; Lanarès 2009) besides a few Sub-Saharan African (Ansah 2015; Ntim 2014) and Asian nations (Krouglov 2017; Quyen et al. 2017; Jawad et al. 2015). Even though it has indeed been recommended for organizations to pay more attention to the development of appropriate QC (Dellana and Hauser 1999) in their effort to the management of QA mechanisms, there seems to be a gap in the literature considering staff perceptions indispensable in developing a QC in HEIs, specifically in the context of Bangladesh.

It is also worth reflecting that the discourse and elements of QA are framed within neoliberal perspectives that highlight particular concepts of accountability, values, and sustainability, which might not align well with efforts within critical approaches to HE governance and platform capitalism, and the logic of it. However, as these concerns are coming from the place of Western academia that has already undergone a number of QA changes, what is here observed as QA in Bangladeshi context is at the level of initial reforms in non-Western national context, under the pressure of Western-induced globalization and university competition. From that perspective, South East Asian universities are left in a precarious position of no choice but to compete, and assure they can improve their global standing.

\subsection{Quality assurance frameworks (QAFs) and their utilization}

The rise of demand for QA processes in HE has directly been linked to massification, to the increase of investment, and to doubts regarding the possibility of maintaining quality amidst dynamic circumstances, as well as to the credence in the importance of $\mathrm{HE}$ in a diversified and internationalized knowledge society (EUA 2010). Against the backdrop of an ever-changing landscape of HE, there is a significant variation of opinions in terms of how QA in HE is predicated on its perceived capacity to guarantee and enact stakeholders' expectation of quality (Ansah 2015). It has also become a key concern among policymakers at the local, national, and institutional levels as a variety of political, economic, and sociocultural forces have accentuated the establishment of 
stringent external quality assurance structures and effective internal quality management mechanisms within educational institutions (Brookes and Becket 2007).

QA mechanisms first came into being nearly three decades ago in 1990 in the USA when the federal Department of Education required recognized accrediting organizations in HE to include the assessment of student learning outcomes in the standards against which they reviewed institutional performances (Ewell 2010). Nine years later, the Bologna Process had been instrumental in setting the standards and guidelines for a QAF in the European Higher Education Area, leading to the inception of the Tuning Project in 2000. The project developed further as a methodology tuning structures and building QC in HE, transcending beyond the geographical boundaries of Europe to create a network of interconnected communities of practitioners across the USA, Latin America, Russia, Africa, China, and Central Asia.

Across nations, the QAFs set the premises for quality control mechanism and standardization of the system through a common accreditation system. Both mandatory and voluntary QA processes in HE are practiced throughout nations around the world with the aim to assure and safeguard academic quality and standards of learning opportunities besides promoting systematic as well as continuous enhancement while ensuring that information about programs are accessible and fit for all purpose. Indeed, best practices for QA require clearly defined and transparent code of practice on criteria that serve as reference point for evaluations and reports of programs offered by HEIs either in a global, national, local, or glonacal context (Hou et al. 2014). For instance, the UK Quality Code sets out a wide range of guidelines which HE providers are required to meet to ensure appropriate and effective teaching, support, assessment, and learning resources are provided, monitored and continually improved for students. Similarly, the Australian Higher Education Standards Framework, legislated by Tertiary Education Quality and Standards Agency (TEQSA 2015), pinpoints a definitive set of threshold standards and processes required to be fulfilled by every Australian HEI. As QA is about ensuring that there are mechanisms, procedures, and processes in place to ensure that the desired quality, however defined and measured, is delivered (Church 1988), many Asian nations like Singapore, China, Hong Kong, Japan, Malaysia, Taiwan, Indonesia, Philippines, Cambodia, and Vietnam have developed their own QAF over the past decade. Subsequently, regional cohesion has been fostered through the establishment of the Association of Southeast Asian Nations University Network-a multinational QA system, which have been influential in developing cross-border student

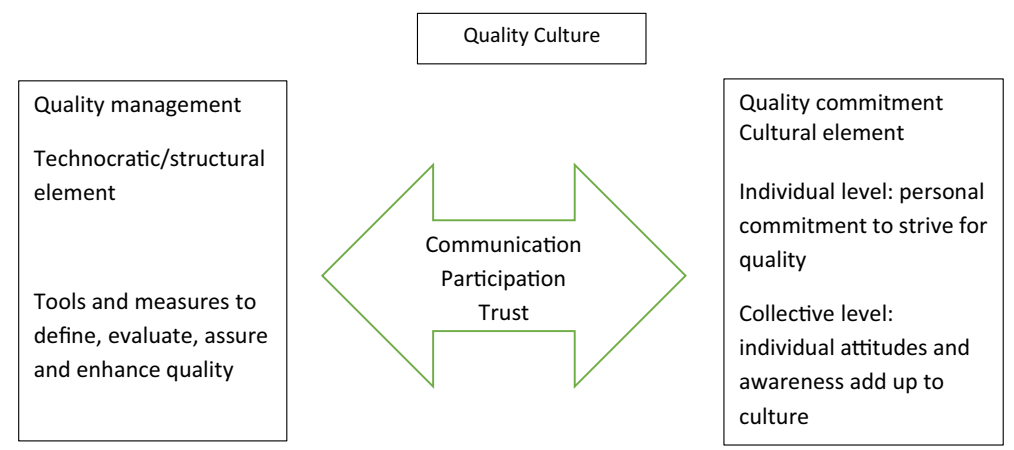

Fig. 2 Quality culture and quality management. Adapted from: EUA 2006, p. 20 
mobility by sharing common values of the QA system. By seeking to further identify, develop, and perpetuate methods of continuous quality improvement, the broad aim of such a collaborative network has been to elaborate quality tools across the region and in each member state by setting benchmarks. Such criteria range from governance, leadership, and management to internal and external QA assessment and enhancement to student recruitment, assessment, support services and community engagement, curriculum design and review, and teaching and learning as well as research management (see Appendix I).

\subsection{Quality assurance framework in Bangladesh's HE}

Given such contexts to various nations' procedures and policies of assuring and enhancing quality as manifested in their QAF, the government of Bangladesh finally operationalized its very own QAF as part of Higher Education Quality Enhancement Project to ensure that Bangladeshi HEIs adhere to clearly set guidelines for QAE. QAE processes enable the improvement of the quality of HEIs and present them with opportunities for continuous improvement within a common framework for QA systems at national and institutional levels, thus promoting accountability as well as recognition across national borders. The framework is designed and articulated in the Institutional Quality Assurance Cell (IQAC) Operation Manual to ensure that every Bangladeshi HEI meets the expectations and delivers on the vision for HE laid out in the Strategic Plan for Higher Education 2006-2026. While the essential constituent of the QA policy provides the benchmarks or quality criteria within which HEIs have to operate, it simultaneously encompasses internal self-assessment review and monitoring and external quality assurance. The intrinsic goal, therefore, is to operationalize national protocols for a qualification framework in order to be accredited by the newly formed Accreditation Council Bangladesh. To initiate the implementation of the QAF, the Ministry of Education had established the QAU to draw up strategies, policies, and plans for educational reforms. Even though the Accreditation Council Bangladesh Act 2017 has been passed by the Bangladesh Parliament on March 7, 2017, the QAU is still responsible for carrying out capacity-building activities and setting relevant QA mechanisms for HEIs until the full operationalization of the accreditation council. Consequently, under the guidance of the QAU, individual universities have been mandated to establish IQAC — an administrative body of quality management—whose prime responsibility is to initiate, develop, and administer long-term QA mechanisms through the QAF to safeguard quality against predefined benchmarks (see Fig. 3) by providing training to staff while building, monitoring, and evaluating capacity for QAE in each HEI. Initially established with financial assistance from Higher Education Quality Enhancement Project, IQACs have been founded in a total of 69 universities as a permanent entity (World Bank Project Aide Memoire 2017) owing to an administrative order as commencement of an internal QA system in every HEI.

Accordingly, many HEIs in Bangladesh have set up their own internal QA mechanisms operating within the QAF as stated in the IQAC manual to adhere to a set of specified expectations to safeguard their academic standards while improving student learning opportunities. By establishing and fostering a quality learning and teaching environment in congruent with international standards of QA criteria and practices as pointed out in the IQAC manual, the central mission of IQAC has been to promote and 
safeguard inclusiveness, transparency, and accountability among academicians, administration, and students as part of a sustainable mechanism of QAE. Simultaneously, through establishing an effective evaluative framework that provides clear evidence of the efficacy and impact of a HEI's teaching, learning, and assessment policies, IQAC has laid the groundwork for every participating HEI to ruminate on their performances while learning how to better manage and deliver its programs and services through a self-assessment exercise that involves all the stakeholders. In conjunction with a set of standards, quality criteria, and performance indicators, the Self-Assessment Review of programs/institutions has been designed to follow a detailed set of guidelines measuring ten dimensions of quality in Bangladesh's HE (see Fig. 3), providing ownership to HEIs to pay heed to the deficiencies that long needed attention. The QA procedural exercise involved collecting data from relevant stakeholders, and generating and analyzing data through a SWOT analysis in order to prepare the Self-Assessment Review report required to be peer reviewed by a panel of external QA experts before site visit. A subsequent site visit by a team of three assessors - one of them being a foreign QA expert selected from a group of peer academics nominated by QAUinvolved meetings with students and staff, including senior management staff, alumni, and employers. Interviews with relevant stakeholders and other supporting documentation submitted for scrutiny were utilized to validate the information presented in the Self-Assessment Review report to be a true reflection of current practices in actuality. At the end of the visit, the team of the external QA experts evaluated the strengths and weaknesses in programs, physical facilities, and overall quality of education provision using a five-point rating scale: excellent, very good, good, poor, and unsatisfactory. An exit report revealed the grade awarded to the entity by the assessors. About 2 months later, a detailed External Peer Review and Validation of Self-Assessment Report sent to the HEI provided recommendations and guidance to help determine the post selfassessment improvement plan of the entity. A total of 796 such self-evaluation exercises had been undertaken by December 2018, when the project's first phase of QA had officially come to an end. Consequently, the QA strategies mutually recommended by IQAC, self-assessment committee and the QA committee, while being ratified and endorsed by the Syndicate, would ultimately be incorporated into every university's strategic plan and materialized within a culture of quality.

\subsection{Evaluating quality culture as a social practice}

In order to decipher how the utilization of the $\mathrm{QC}$ is translated into practices by the staff at the Bangladeshi HEI, a realist approach (Pawson and Tilley, 1997) was considered suitable in evaluating the success of the practical application of the QAF. In the light of such a perspective, situated representations of values, activities, and social behavior individual actors depict, through their practices in a social domain like HE, are interpreted through a sociocultural theoretical lens. As "constellations of practices" are inherently embedded in societal settings, they are simultaneously "nested" in the cultures on which the practices themselves depend (Saunders et al. 2011, p. 3). And as a justice to the "diversity of experience and the voices of all those in the (evaluation's) orbit," the activities and experiences of the key stakeholders form the center of evaluation while emphasizing on the situated activities (Saunders et al. 2011, p. 9). As cultural phenomena, practices can be conceptualized as (Reckwitz 2002, pp. 249-250): 


\begin{tabular}{|c|c|c|}
\hline $\begin{array}{l}\text { Internal Quality } \\
\text { Assurance System }\end{array}$ & $\begin{array}{l}\text { External Quality } \\
\text { Assurance System }\end{array}$ & Accreditation \\
\hline $\begin{array}{l}\text { Developing the criteria for QA: } \\
\text { Governance } \\
\text { Curriculum Content, Design and } \\
\text { Review } \\
\text { Student Entry qualifications, } \\
\text { Admission procedure, Progress and } \\
\text { Achievements } \\
\text { Physical Facilities } \\
\text { Teaching, Learning and Assessment } \\
\text { Student Support Services } \\
\text { Staff and Facilities } \\
\text { Research and Extension } \\
\text { Process Management \& Continuous } \\
\text { Improvement }\end{array}$ & $\begin{array}{l}\text { External peer review by QA agencies } \\
\text { to: } \\
\text { Identify the strength/weaknesses in } \\
\text { QA practices } \\
\text { Develop a working plan to improve } \\
\text { the QA practices } \\
\text { Safeguard the quality of delivery of } \\
\text { academics } \\
\text { Share good practices in the provision } \\
\text { of education }\end{array}$ & $\begin{array}{l}\text { Recognition of QA practices by } \\
\text { external quality assurance agencies in } \\
\text { accordance to international standard } \\
\text { Gain accreditation from certified } \\
\text { agencies } \\
\text { Developing national Quality Assurance } \\
\text { and Accreditation Council Bangladesh } \\
\text { (ACB) to maintain and enhance quality }\end{array}$ \\
\hline
\end{tabular}

Fig. 3 The Bangladeshi HE Quality Assurance Framework. Adapted from: IQAC Operations Manual, 2014. Adapted from: McLaughlin and Jordan 1999

a routinized type of behaviour which consists of several elements, interconnected to one another: forms of bodily activities, forms of mental activities, 'things' and their use, a background knowledge in the form understanding, know-how, states of emotion and motivational knowledge

A social practice approach to evaluation, nevertheless, evolves in a setting where multiple stakeholders operate, have their voices heard, engage and participate in evaluation as practitioners, and learn in the process. The practice approach is attached to "whatever it is that people do as a response to a policy, an intervention, opportunity or initiative, and this constitutes an inductive method" (Saunders 2011, p. 93).

\subsection{Evaluation of quality culture: developing a logic model}

To sustain any quality effort, it is vital to develop a culture since achieving cultural change is central in total quality management (Dale et al. 1997) in any organization. Logic models present a more vivid picture of programs while being utilized to build a common understanding of programs and expectations among stakeholders, designs and means of improvement, enhanced collaboration and support for, and promotion of clear communications about programs (McLaughlin and Jordan 1999; Millar et al. 2001; Price et al. 2009). Used widely and successfully in fields of business, health, and education programs, the logic model is a systematic visualization tool which forms a basis for any evaluation and delineates the pathways of inputs, outputs, and conceivable outcomes to validate the rationale behind any project. The model is defined as "a graphic representation of a program that describes the program's essential components and expected accomplishments and conveys the logical relationship between these components and their outcomes" (Conrad et al. 1999, p. 18). Such a roadmap makes "transparent the theory of action of a program, that is, how program activities or 
processes are supposed to work in order to accomplish the program goals or outcomes" (Newton et al. 2013, p. 90). As its most common usage is to explicitly outline any program from its initiation to completion, with a focus on the available resources and activities that will enable it to achieve its desired results (Price et al. 2009), professional evaluators duly utilize logic models to facilitate evaluation. The key elements of a logic model comprise of its inputs (resources or investment supporting the program), activities (program implementation), outputs (evidence or products of the activities), and lastly outcomes (changes as reflected in the outputs). Such models "generally depict the logical series of events from program intervention to program outcomes" (Millar et al. 2001, p. 74) as the key components are operationalized by identifying intervening steps of utilizing the inputs, implementing the activities, measuring the outputs, and achieving the outcomes. Implementation of a logic model process can facilitate "communication, cooperation, and shared understanding among different levels of management and staff' (Savaya and Waysman 2005, p. 94) within an institution. Therefore, by engaging in the process of creating a logic model to map the factors that may influence the development of QC in the HEI as perceived by staff, this paper highlights on the effectiveness of QAF in developing a QC while systematically addressing the change strategy besides important planning and evaluation issues.

\section{Methods}

\subsection{A qualitative research design: institutional context, participants, and ethical considerations}

As this study shed light on staffs' perceptions of the attainments and the challenges in QA, "efforts [were] made to get inside the person and to understand from within" (Cohen et al. 2000, p. 22) for a rich as well as deeper understanding of the complexities in the construction and reconceptualization of their role in institutionalized QC and their relationships with social realities of QA that is constantly "in the making" (Elliott 2005). Because qualitative methods are better suited for exploring beliefs and opinions (Scott 2003), techniques were adopted not only to "investigate a contemporary phenomenon within its real-life context" (Yin 2014, p. 13), but also to construct a multidimensional representation of individual perspectives, interpretations, and perceptions of "seeing the world through his eyes" (Corbetta 2003). With this in mind, the study drew on a thematic analysis of interview accounts of academic/administrative staff as they captured the complexities of their individual experiences and expressed their own understanding of social realities in their own terms (Patton 1990). A social practice account was utilized to provide a more expansive framework for understanding how persons and practices are mutually constituted. By offering a lens for interpreting pathways to develop and enhance QC across the HEI, a social practice theory highlights staff agency and its relationship with structures of practice.

The study was centered on a private university, located in Dhaka, the capital of Bangladesh. The rationale behind the choice was a practical one based primarily on convenient access, geographical considerations, and in relation to obtaining appropriate permissions of data collection. The mission of the university in question is twofold: "achieve the goals of higher education and sustainable economic growth in the 
country" by producing graduates with "knowledge and relevant skills to provide leadership in enterprise, public service and welfare." The university has six academic divisions with ten departments. Each academic school/faculty is managed separately and is headed by a dean as an administrator who reports to the Vice-Chancellor, directly appointed by the Chancellor, the President of Bangladesh, for a 4-year term. The ViceChancellor has ultimate responsibility for the overall academic and financial well-being of the institution and is accountable to the Board of Trustees. Within the schools, each department is managed by a Head who reports directly to the Dean. The head of each department is responsible, through consensus building among the faculty, for developing and overseeing academic programs, mentoring faculty, and providing the managerial expertise needed to achieve goals for departmental programs. The schools, however, share systems for financial management and human resources, such as staff recruitment and promotion.

In accordance with issues of ethics, the study obtained university ethical clearance. Participation in the interviews was voluntary and prior to the study informed consent was obtained from all individual participants involved in the study. The participants were ensured that their participation involves no foreseeable social, cultural, political, or institutional risk. All were given the opportunity to decline to partake in the study at any time. In the dissemination of findings from the study, the confidentiality of individual participants was ensured, and any personal identifier was removed. A total number of 15 academics and 12 administrators were randomly selected (Kazdin 1992) from the staff directory of the HEI and invited to individually participate in a face-toface interview (see Appendix II). Of them, only six academics and four administrators agreed to participate in the study. The academics, four female and two male, were from two different disciplines. They had all actively participated in the initial QA procedural program self-assessment review exercises which involved collecting data from relevant stakeholders, and generating and analyzing them in order to prepare the self-assessment review report required to be peer reviewed by a panel of external QA experts. The four administrators who oversaw four different faculty were all male (see Table 2).

\subsection{Interviews}

At the outset, secondary data sources, such as government documents and literature on Bangladesh's HE system, were utilized to set the national and institutional contexts for the QAF system. Subsequently, interview questions were developed to guide the primary data collection process. Interview questions were semi-structured and aimed at eliciting practical information from respondents so as to inform practices with evidence of commitment to quality and challenges in the promotion of QC. Thus, questions were developed to elicit staff's personal attitudes, beliefs, interpretations, and responses regarding various issues of QC including governance, teaching-learning, program management, faculty research, code of conduct, and code of practice. The first two questions focused on individual interpretation of what QC means to a staff and their perception of that QC in relation to the implementation process of the Quality Assurance Framework being developed in the institution. The third question focused on the perceived challenges of the quality assurance system that might hinder the development of QC at the HEI. The fourth sought to obtain insights about the indicators of successful implementation of QC at the institution. The final question addressed the 
staff perception of the institutional role in supporting the development of a QC. The interviews, which lasted between 30 and $45 \mathrm{~min}$, were targeted to evaluate how the self-assessment exercises, along with external peer review and processes of accreditation, have encouraged a culture of compliance to QA at the HEI. Digitally recorded and anonymized accordingly, the interviews particularly sought to investigate the developmental challenges in the QA system that could instill internal QC among the employees of the HEI. The interviews were transcribed verbatim, with more emphasis on the significance, rather than grammatical accuracy.

An in-depth analysis of the interviews was undertaken concurrently with the data collection in an iterative cycle to document the researcher's interpretation of emerging themes and to identify perspectives that otherwise may have been overlooked (Sargeant 2012). Thus, at the preliminary stage of analysis, the interview transcripts were closely studied and annotated by using NVivo - a qualitative data analysis software - for initial coding of each individual interviewee's transcription as well as for organization of data with regard to themes (see Table 3). Categorized as dimensions of QC, examples of various enablers were extracted from the recorded responses almost verbatim (Maykut and Morehouse 1994). While the transcribed texts were unitized into "one identifiable idea" (Aviv 2000, p. 59) through a thematic analysis (Braun and Clarke 2006), the descriptive extracts of the participants were analyzed and particular attention was paid to the ways the participants perceived the challenges, concerns, and perspectives in terms of what was instrumental in assurance and enhancement of quality in Bangladesh's HE. Finally, notes were compiled and collated in support of the analysis of the data.

\section{Results}

An elaborate mapping of staff perceptions of the factors driving the development of QC at the Bangladeshi HEI is delineated through an analysis of the responses to the interviews. The following part of this paper moves on to describe, in greater detail, the values and strategies as well as expectations raised by the staff at the Bangladeshi HEI in terms of quality management and enhancement. As the macro trend in Bangladesh's HE policy reforms redefined the trajectory of QA policy at the mesolevel of the HE providers, it has been crucial to chronicle the challenges and successes regarding change in staff attitude, beliefs, and behavior in relation to micromanagement of quality at HEIs. While evaluating the enablers of quality at the Bangladeshi HEI, five key dimensions of QC were identified from the interviewees' responses, objectively tangible in terms of the tools and procedures (artifacts) of quality management (Sattler and Sonntag 2018): staff motivation and engagement, culture of research and evaluation, transparency in information exchange and knowledge of QA processes, effective leadership, and student focus.

\subsection{Staff motivation and engagement}

The majority of the faculty who were interviewed felt that staff members must be intrinsically driven by a passion to teach as well as improve teaching through continuous research and as source of satisfaction and that they should extrinsically be motivated through recognitions by means of performance awards as well as monetary 
Table 2 Participants' profile

\begin{tabular}{lll}
\hline Name (pseudonyms) & Role & Experience in the current role (years) \\
\hline Nadia & Teaching & $1-5$ \\
Maya & Teaching & $6-10$ \\
Maher & Teaching & $20-25$ \\
Jessie & Teaching & $11-15$ \\
Samantha & Teaching & $16-20$ \\
Sadat & Teaching & $11-15$ \\
Hamid & Management & $6-10$ \\
Kabir & Management & $6-10$ \\
Musa & Management & $6-10$ \\
Mahir & Management & $1-5$ \\
\hline
\end{tabular}

rewards owing to their personal growth. Thus, an interviewee commented, "Unless good practices are evaluated and incentivized, how can one ensure the delivery of quality professional services?" Such institutionalized reward and recognition system is instrumental in creating a work environment that promote QC, she stated.

All the interviewees alluded to the notion that employee engagement is key in nurturing a sustainable QC in the HEI. And change to an HEI's culture, though directly related to the values, beliefs, and mindset of the staff members, is a difficult and slow process. However, according to the interviewees, a lack of dialog and consultation among administrative, academic staff, and the senior management leader could lead to a lack of trust which in turn leads to lack of ownership in the QA process. Therefore, the participants reemphasized that proper communication flow among the senior, mid, and entry level must be established to share best practices, resolve issues, and reassess the effectiveness of quality measures.

\subsection{A culture of research and evaluation}

While the academics acknowledged that a strong research and evaluation culture is crucial in raising research productivity to correlate with quality teaching and learning as well as societal use and benefits, a clear blueprint must be in place which would reflect the HEI's vision for a sustainable cultural change to use evaluation and research findings to inform key decision-making in curriculum design as well as teaching and learning. A common view among interviewees was that, besides professional development activities, the HEI also needs to allocate and provide adequate financial and stateof-the-art infrastructural resources based on motivations and abilities for research, particularly for early and mid-career faculty members, while ensuring accountability of the staff to research outcomes at the same time.

However, most of the academics alluded to the necessity of creating a culture by providing assistance as well as resources that support "employee mental well-being" for a healthy workplace where faculty members can "being their whole selves to work." Since faculty members balance multiple roles as teachers, researchers, mentors, and managers, it is not uncommon for faculty to experience "stress and anxiety" and 
Table 3 Dimensions of quality culture

\begin{tabular}{ll}
\hline Themes & Subthemes \\
\hline Staff motivation and engagement & Shared accountability \\
& Spread sense of ownership \\
& Clear flow of communication \\
& Culture of excellence \\
A culture of research and evaluation & Teaching demand vs. research productivity \\
& Institutional collaborations and professional associations \\
& Continuous cycle of learning and improvement \\
Transparency in information exchange & Open discussion of quality \\
and knowledge of quality process & Explicit prioritization of quality \\
& Awareness of role clarity \\
Less bureaucratic \\
Effective leadership & Leaders empower staff with greater autonomy \\
& Staff taking the ownership and embracing accountability \\
& Leaders as a mentor and as source of inspiration \\
Leaders as role models & Students playing a central role \\
Student focus & Deep student insight \\
&
\end{tabular}

"burnout" while struggling to meet "work demands" of teaching larger classes. Unless teaching loads are reduced and educational or sabbatical leave schemes are designed to give motivated, early, and mid-career faculty more time to undertake research, publication rates will also remain "a sorry state of affairs" while nullifying the effectiveness of QAE. An interviewee further indicated that HEIs should have a wide range of faculty awards based on the assessment of their teaching performances besides promotion of faculty research productivity to create a rather "balanced" culture of excellence in teaching, research, and social services.

While talking about the issue of research, an interviewee added that Bangladeshi HEIs could actively begin to establish transnational institutional collaborations and professional associations to foster competition while supporting the development of faculty by increasing teaching productivity and research output, creating networks through sponsorship of faculty participation in conferences and even hosting them. Furthermore, one of the administrators expressed the belief that faculty with minimal research output will likely need training and personal support from their institutions to become proficient. He further added that Bangladeshi HEIs will have to establish research centers to support both staff and student services in developing more interdisciplinary research practices while embracing Bangladeshi cultural ideals that embody traditional values. Such establishment, he specified, could also provide assistance with grant writing and continuing education courses while simultaneously moving toward greater student involvement in a culture of research through the availability of research assistantships.

\subsection{Transparency in information exchange and knowledge of quality processes}

Although an "experienced senior" academic staff believes that quality is the responsibility and administrative function of the quality department, others pointed out that 
despite their awareness of the "bureaucratic exercises involved in QA through a topdown approach," there ought to be "greater mediation through effective communication and participation" among leaders, staff members, and students as well as external stakeholders/agencies. They pointed out that the nine key QA areas (see Appendix I) and the 46 quality-related criteria issued by the Ministry of Education in Bangladesh set standards that appear "rather idealistic" given the heavy teaching loads of most lecturers in Bangladeshi HEIs, and the absence of a sufficient working space for lecturers.

They noted that a greater degree of external communication, even beyond national boundaries, will ensure better accountability and foster evaluation and assessment on a global level. However, an academic noted that excessive bureaucracy might have a negative impact on the development of a QC as staff are only "supposed to do what they are told to" and might only have "administrative issues sorted out" just before self-assessment exercises prior to the external peer review of programs at HEIs. And while reports of the EPR of programs are often not explicitly shared with staffs at the grassroots level, academic staff are often left with limited ideas and no sense of direction in some cases as to "what quality goals they must accomplish and in what way" and how "group and individual performances are measured, rewarded or even penalized." Thus, according to an administrator, the QA report should be clearly "understandable," "engaging," and "accessible," and the impacts of its quality measures "assessable" at the same time. Since at the heart of quality culture lies the issues of reflexivity and praxis that help develop quality enhancement initiatives, it is instrumental for any quality system to be less bureaucratic and having a clear purpose.

\subsection{Effective leadership}

All the interviewees emphasized that leadership plays a key role in establishing and sustaining QC through effective communication and safeguarding quality mission, vision, and values. While the leadership would be committed to managing clear quality goals, playing a crucial role in enabling capable resources, the staff must also take the ownership of working toward accomplishing those set objectives. However, interviewees in academic roles pointed out that staff at the grassroots level are not fully aware of how they might contribute to achieving the quality vision of the HEI. While values and expectations are not established and widely communicated among the staff, employees are often not "told" how they might work toward the mission of the HEI: "You say quality comes first but how do we know what to do unless you walk the talk and demonstrate quality in action...." One of the interviewees in a key leadership role, however, felt the need for leaders to equip, educate if necessary, and finally shift responsibility and empower employees by giving them autonomy to work toward the common goals of teaching, learning, and research in the HEI. Leaders, to him, must essentially create the work environment that promotes team spirit for growth. He stated that such leaders are always an inspiration for every employee to emulate to improve and enhance quality of teaching and learning and student satisfaction. And when leaders actively participate in quality audits, it inspires people to open up with their suggestions and observations, he further added. Since a QC is about 
partnership, teamwork, cooperation, and sharing of experiences, an inspirational leadership, rather than dictatorial, can help develop a less bureaucratic system which still administers quality monitoring to ensure accountability and compliance while facilitating improvement.

\subsection{Student focus}

The staff unanimously emphasized on the importance of having students voice their satisfaction, experiences, and expectations in the quality management of teaching and learning as one of the most important stakeholders in a HEI. Through effective student engagement, according to them, an HEI can improve the quality and efficacy of their course design, teaching strategies, and assessment practices to produce more meaningful outcomes for students. Even though a mandatory faculty evaluation is in place in most of the Bangladeshi HEIs, it is crucial, according to the respondents, to collect feedback specially from final year students about their overall experiences on their program of study. As prospective students need clear information about what to expect from $\mathrm{HE}$ in terms of contact with tutors, availability of independent learning resources, digital, language, and writing support, feedback on work, and so on, such accessible and open feedback could help prospective students make informed decisions about choosing where to study while providing the university with a sense of direction toward developing an even better student experience for all. Since QC is primarily about the behavior of stakeholders rather than the operation of a quality system, by placing students at the center to take academic ownership, quality could cultivate a proactive QC.

\section{Discussion}

The overall findings of this study manifest staff perceptions of the social realities prevalent in Bangladeshi private HEIs and the move toward embedding values of QC in the nation's journey toward QAE. As a strong QC no longer requires just a QA system but is based on mutual trust between all stakeholders of the educational process, it is built step by step, never enforced, until it evolves into a systematic continuous enhancement process in reality (Adina-Petruţa 2014). On the grounds that the primary responsibility for QA in HE lies with each institution itself (BPMC 2003), it is indispensable to embed QC as a key ingredient of institutional ethos.

Since the participants in this study highlighted on their perceived challenges for efficacious implementation of the QAF in Bangladesh, they emphasized particularly on the key importance of staff capacity-building and staff involvement (Ansah 2015). The evidence presented has shown that the participants strongly regarded staff development as a major requirement for increasing the quality of staff and embedding QC. Therefore, there must be - on a permanent basis - staff development schemes that include training, funding for participation in international conferences, and so on for developing skills, strengthening accountability and QA while increasing the motivation of staff (EUA 2006, p. 22).

In accordance with the present result wherein participants have also commented on the role of leadership, it is apt to state that the fundamental aspect of QC as an 
organizational subculture (Lanarès 2009) is an entailment of equal contribution from all individuals, committed to a process of continuous improvement which in turn requires "leadership and management of a high order" (Yorke 2000). Indeed, through a devolution of responsibility (Harvey and Green 1993), a culture of quality in any organization ensures that every personnel, not just the quality controllers, is responsible for constant engagement with quality (Crosby 1986) and excellence in terms of specifications and processes. As such, without the full ownership of the stakeholders in the QA processes, there is but risk of an empty bureaucratic exercise having little impact on the enhancement of quality (ENQA, ESU, EUA et al. 2014, p. 6). While Bangladeshi HEIs learn to cater to the needs and requirements of their various stakeholders including staff and students, they gain reputations with regard to QA within a self-perpetuating institutionalized QC. And for quality to be intrinsically built in the OC of a HEI, it is essential to develop a learning and teaching strategy which needs to extensively involve staff and students for grassroots development of quality rather than a top-down approach to achieving quality goals. Unless HEIs do not develop their own QC, the efforts of QA will essentially be nullified.

A key issue in creating or developing a QC is therefore to make all these values and priorities explicit and identifiable so as to infuse the quality concept and its operations while influencing collective and individual practices (Lanarès 2009). And while developing a QC means evaluating the evolution of all these values as a whole, indicators and dimensions of quality in the prevailing culture of a HEI, the results of this study, as being mapped within a logic model, can be used as an effective evaluative tool. More importantly, evaluation is deemed to be effective within a set of social practices in an organization as part of a cultural orientation rather than "performance ridden raft of controlling measures and systems" (Saunders et al. 2011) which encompasses a shared commitment to QA, grassroots involvement of staff and students, and an adequate balance between top-down and bottom-up improvement initiatives (EUA 2006).

A careful analysis of the drivers, based on the researcher's interpretation of interview data, suggests that approaches to QAE processes must find ways to combine both macro- and meso-level factors to impact the quality of student teaching and learning as well as research at the micro-level as solutions for building an effective QC. Even though the factors might operate at various levels, their interdependence can be traced within the framework of a clearly defined logic model as shown (Fig. 3). Since social practice theory emphasizes that it is through these engagements with practices that individuals come to understand the world around them and develop a sense of self (Warde 2005), the focus is shifted from individual attitudes and behavior to highlight how practices are formed, reproduced, maintained, and challenged as Bangladeshi practitioners contest and resist conventions in the face of new policy implementation (Hargreaves 2011).

Therefore, in Fig. 4, the findings of the analysis are integrated into a logical model of quality culture by McLaughlin and Jordan (1999). While any quality system needs to have a clear purpose that articulates with the QC, such a graphic 
display or conceptual mapping of the relationship between resources, activities, and intended results can foreshadow what changes are expected to be delivered. The process of creating a logic model is considered to be valuable as it requires programs to clearly articulate vision and aims while drawing out gaps between the constituents of the system, the underlying assumptions and the anticipated outcomes (Helitzer et al. 2010), thus introducing a more structured and standardized approach to evaluation. As the process of developing the QC logic model for a Bangladeshi HEI creates shared understanding and clear expectations of the vision, activities, roles, and responsibilities between the stakeholders (Jordan 2010), it can help create a valuable evidence base by establishing the effectiveness of the QAF in developing QC among Bangladeshi HE.

For now, recent reforms in Bangladesh's HE through the implementation of the QAF is only a stepping-stone toward gaining confidence of the stakeholders in a globalized setting by ensuring best practices with transparency, accountability, and credibility in accordance with internationally acceptable practices. As Bangladesh stands on the historical pathway to HE reforms by choosing to begin with an overhaul of both national and institutional HE infrastructures, a vital undertaking is to assure quality while continuously improving the performances of HEIs to gain the confidence of both local and international market spaces through graduate employability and transnational accreditation.

While Bangladeshi HEIs begin to adhere to the QA mechanisms as opportunities for learning and capacity building rather than an act of compliance amidst a tick-box culture, these HEIs can eventually become self-regulators while operating in a work environment embedded in a culture of quality. As these HEIs bring more autonomy and a greater sense of accountability, the government can eventually loosen control toward a decentralization of Bangladeshi HE system. And with a robust and sustainable QA system in place, Bangladeshi HEIs would eventually move toward internationalization and a greater mobility of students as they would create networks and opportunities for exchange and partnership especially in the Asian region to begin with. When the initial phase of this historical QAF eases out, many Bangladeshi HEIs, in their response to glonacal trends, would seek international recognition rather than national, local, or regional accreditation to enhance academic competitiveness globally (Deem et al. 2008) while increasing reputation to safeguard enrollment (Hou et al. 2014) and to share world league space just as countries like Singapore, South Korea, and Taiwan amidst Western dominance.

However, as Bangladesh continues to further strengthen its QA practices, HE policymakers and stakeholders would need to be convinced that it is necessary to attain some international convergence following generic international quality guidance and practices developed by international or supra-national bodies such as the United Nations Educational, Scientific and Cultural Organization, the World Bank, or the Organization for Economic Co-operation and Development to remain connected and current in education trends (CHEA 2014). QA processes are considered to be non-static and often nations manifest proselytizing 
tendency of cut-and-paste QA policy-making, leading to tightening standards (Sursock 2012) which work alongside QA processes to greatly impact HEIs by warranting accreditation. Notably, accreditation confirms a HE provider's reputation as a quality provider of a particular program responsive to industry needs and in line with shared practices in a global academic community, thus supporting and signposting graduate employability. As the QAF is still not comprehensive in nature with transparent information on procedures of QA arrangements (see Appendix I), accreditations, and recognition of qualifications, efforts are needed for further international as well as regional networking and collaboration that can help a developing nation like Bangladesh set benchmarks and clear subject specifications toward a more systematic qualification framework, comparable at a global level while promoting increased cross-border
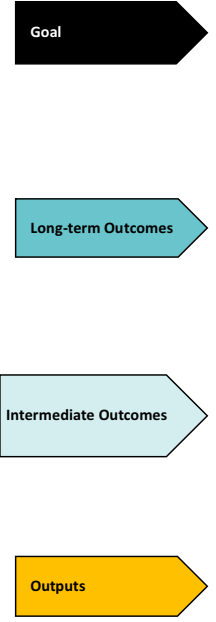

Activities

Inputs
Develop, strengthen and sustain an ecosystem of quality in Bangladeshi HEls

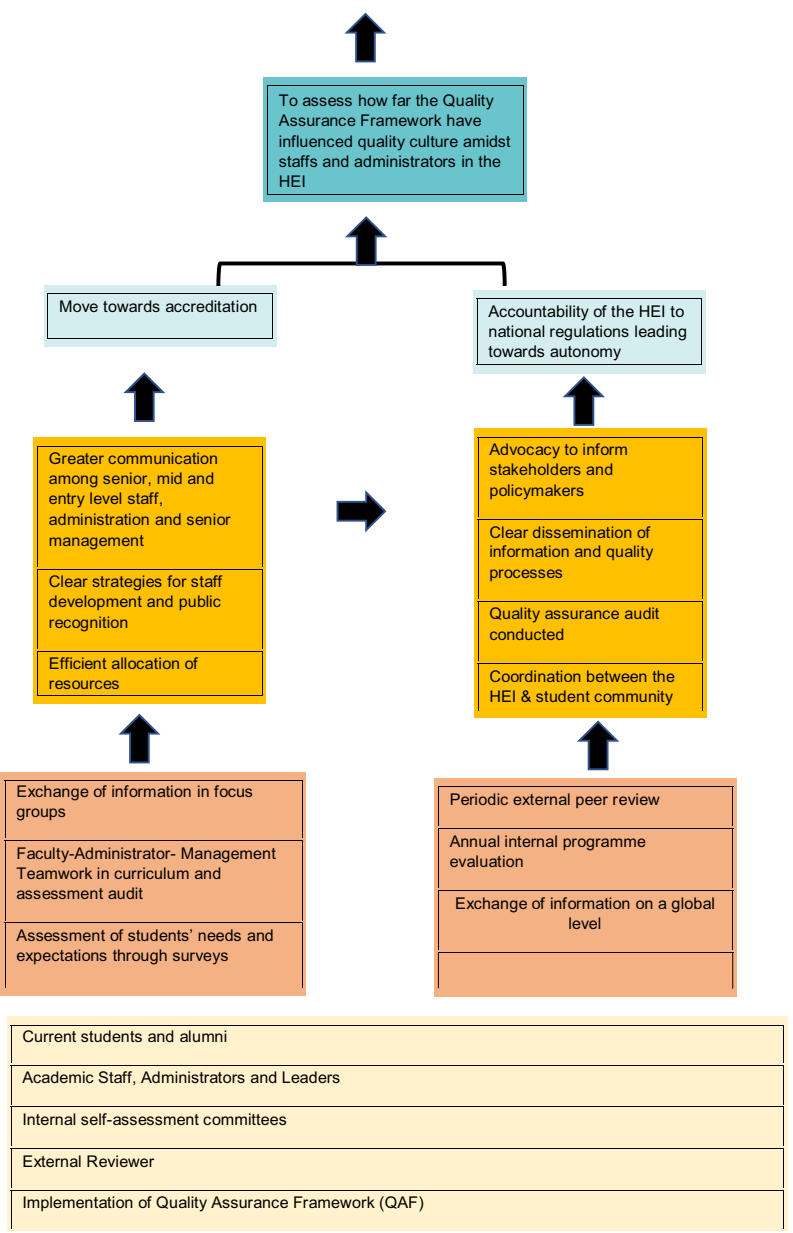

Fig. 4 Evolution of quality culture at an HEI: a logic model 
mobility of students as well as academic staff and professionals (UNESCO 2005).

\section{Limitations of the study}

However, the findings of this study have to be seen in light of some limitations. The primary limitation concerns the need to critically reflect and examine the proposed constructs of QC. Although, there is evidence that some key aspects of HE cannot be measured and the hierarchy of what is important and what is not can damage the value of $\mathrm{HE}$ as much as it can help organizational functionality, developing appropriate and measurable indicators is the key to a robust evaluative culture in organizations. And evaluation has been regarded not only as a scientific and technical affair but a routinized social practice in itself (Abma and Widdershoven 2008, p. 121) comprising of practices that use implicit, tacit, or unconscious knowledge. While it is paramount to address vital factors and operative steps for assessing organizational readiness for cultural change in the implementation of QAF, it is equally important to strategically explore the relationship among institutions' human resource, administrative, financial, and technical capacities and the adoption of quantifiable outcomes which otherwise will have little cogency unless the staff see its value in impact and decision-making (Poole et al. 2001). The secondary limitation to the generalization of the results of this study is due to its small sample size. Even though the scope of this study is limited, it is but the first phase of exploration in capturing staff perception in the light of the implementation of the overarching QAF that has coalesced in less than a decade. At this juncture, therefore, attention needs to be on QAF implementation issues besides quality enhancement and management. Further studies need to be carried out to consider quality as being practiced in Bangladeshi HE amidst its various assurance and accountability measures, competition, and internationalization and how such constructs can affect staff, for example, and what all that can mean in terms of staff work and their teaching workload in correlation to their research productivity, as well as their mental well-being.

Finally, as mentioned earlier, caution should be taken with regard to mainly neoliberal informed applications of Higher Education QA reforms in nonWestern context, as the pressures by global leading universities and HE systems coming from the Western context are huge, and this needs to be acknowledged. Bangladeshi as well as other global universities would need to be mindful of their higher education and knowledge paradigms adopted, as well as keep an eye on pressing global challenges, such as ecological sustainability and social inequality. Although these are not tackled in this article, this area is acknowledged and deemed as the article's limitation. 


\section{Conclusions}

In conclusion, this paper has provided an insight into staff perception of values, expectations, and challenges relating to Bangladeshi development of a QC. Owing to the recent implementation of the state-stipulated QAF, the need for institutional evaluations for accreditation toward more autonomy has endowed Bangladesh's HEIs with a greater share of responsibility in facilitating the creation of QC, previously unheard of. In these contexts, as the QAF undergoes developments and further revisions owing to program as well as institutional evaluation, accreditation, or audits (ENQA 2008, pp. 25-26; Hopbach 2011), policymakers would need to be apprised of the changing trends in HE and consider how QA could be used to support them. In relation to the dimensions and values of quality as classified from the narratives in this study, the next way forward is to have a large sample of respondents from several Bangladeshi HEIs undertake a Quality Culture Survey which will take these perceptive variables into account and evaluate Bangladeshi HEIs' feat with the QAF.

While the most common purposes of QA are accountability and enhancement, HEIs demonstrate their accountability through successful implementation and continuous enhancement of effective QA mechanisms which support the development of a QC within HEIs by means of more increased engagement of all stakeholders. As complex organizations, private HEIs in Bangladesh are mandated by the state to continually enhance and maintain their quality of education and research, originating from a $\mathrm{QC}$ based on core values (Lycke and Tano 2017) of learning organization, leadership commitment, and formal QA processes. Since QC in an institution manifests "an internality that supports its staff in the fulfilment of their duties" (Yorke 2000), the logic model is useful for identifying elements that are most likely to help develop the QC. Early identification of such baseline factors can yield useful evaluation data and identify appropriate sequence for collecting data and measuring progress and impact (McCawley 2002). Therefore, as Bangladeshi HEIs and their stakeholders approach the QA and accreditation process as opportunities for learning, capacity building, and improvement of quality levels through a sustainable internal QC rather than an act of compliance, the HEIs can eventually become self-regulators. And as the HEIs strengthen institutional autonomy and foster greater sense of accountability within a culture of quality, the government of Bangladesh can eventually loosen control toward a decentralization of Bangladeshi HE system. With robust and sustainable QA mechanisms in place, Bangladeshi HEIs would eventually move toward internationalization and a greater mobility of students as they create networks, opportunities for exchange, and partnership first of all in their local Asian context, and beyond. 


\section{Appendix I Higher Education Quality Assurance Framework Across Nations}

\begin{tabular}{|c|c|c|c|c|}
\hline $\begin{array}{l}\text { Standards and Guidelines for } \\
\text { Quality Assurance in the EHEA }\end{array}$ & $\begin{array}{l}\text { UK Quality Code - Part B } \\
\text { Assuring and Enhancing } \\
\text { Academic Quality }\end{array}$ & Institutional QA - TEQSA & The ASEAN Framework for IQA & $\begin{array}{l}\text { The Quality Criteria in } \\
\text { Bangladeshi QAF }\end{array}$ \\
\hline 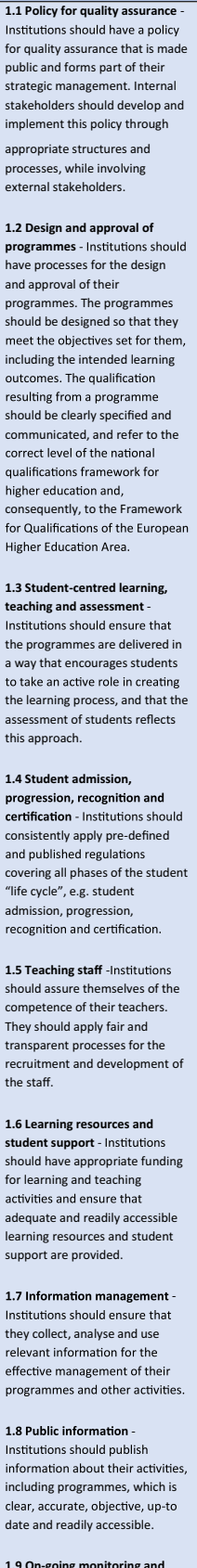 & 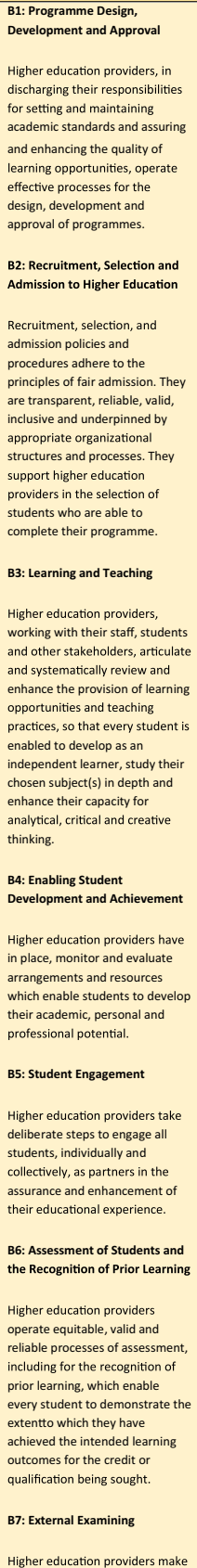 & $\begin{array}{l}5.1 \text { Course Approval and } \\
\text { Accreditation } \\
\text { Course approval and self- } \\
\text { accreditation processes are } \\
\text { overseen by peak institutional } \\
\text { academic governance processes } \\
\text { and they are applied consistently } \\
\text { to all courses of study, before the } \\
\text { courses are first offered and } \\
\text { during re-approval or re- } \\
\text { accreditation of the courses. } \\
5.2 \text { Academic and Research } \\
\text { Integrity } \\
\text { There are policies that promote } \\
\text { and uphold the academic and } \\
\text { research integrity of courses and } \\
\text { units of study, research and } \\
\text { research training activities, and } \\
\text { institutional policies and } \\
\text { procedures address misconduct } \\
\text { and allegations of misconduct. } \\
\text { 5.3 Monitoring, Review and } \\
\text { Improvement } \\
\text { 1. All accredited courses of study } \\
\text { are subject to periodic (at least } \\
\text { every seven years) } \\
\text { comprehensive reviews that are } \\
\text { overseen by peak academic } \\
\text { governance processes and } \\
\text { include external referencing or } \\
\text { other benchmarking activities } \\
5.4 \text { Delivery with other Parties } \\
\text { 1. Work-integrated learning, } \\
\text { placements, other community- } \\
\text { based learning and colllaborative } \\
\text { research training arrangements } \\
\text { are quality assured, including } \\
\text { assurance of the quality of } \\
\text { supervision of student } \\
\text { experiences. }\end{array}$ & $\begin{array}{l}\text { 3.1. The institution has primary } \\
\text { responsibility for quality. } \\
\text { 3.2. Quality assurance promotes } \\
\text { the balance between institutional } \\
\text { autonomy and accountability. } \\
\text { 3.3. Quality assurance is a } \\
\text { participatory and cooperative } \\
\text { process across all levels } \\
\text { incorporating involvement of } \\
\text { academic staff, students, and } \\
\text { other stakeholders. } \\
\text { 3.4. A quality culture underpins } \\
\text { all institutional activities } \\
\text { including teaching, learning, } \\
\text { research, services and } \\
\text { management. } \\
\text { 3.5. A structured and functional } \\
\text { internal quality assurance system } \\
\text { with clearly defined } \\
\text { responsibilities is established. } \\
\text { 3.6. The quality system is } \\
\text { promulgated and supported by } \\
\text { the top management to ensure } \\
\text { effective implementation and } \\
\text { sustainability. } 3.7 \text {. Sufficient } \\
\text { resources for establishing and } \\
\text { maintaining an effective quality } \\
\text { system within the institution } \\
\text { should be provided. } \\
\text { 3.8. The institution should have } \\
\text { formal mechanisms for approval, } \\
\text { periodical reviews and } \\
\text { monitoring of programmes and } \\
\text { awards. } \\
\text { 3.9. Quality is regularly } \\
\text { monitored and reviewed for } \\
\text { purposes of continuous } \\
\text { improvement at all levels. } \\
\text { information about the institution, } \\
\text { its programmes, achievements, } \\
\text { and quality processes is } \\
\text { accessible to public. }\end{array}$ & 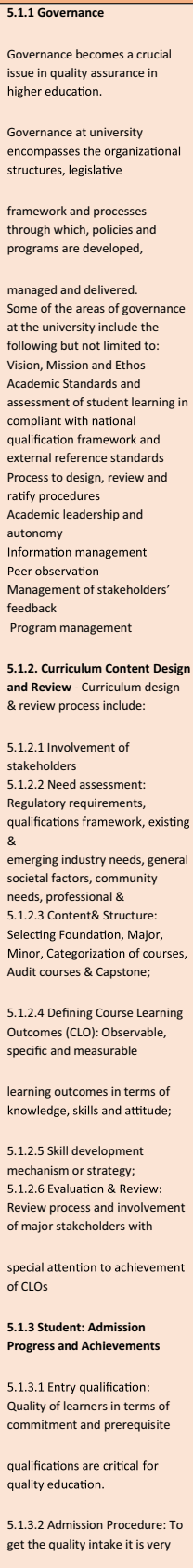 \\
\hline
\end{tabular}




\begin{tabular}{|c|c|c|}
\hline $\begin{array}{l}\text { periodic review of programmes - } \\
\text { Institutions should monitor and } \\
\text { periodically review their } \\
\text { programmes to ensure that they } \\
\text { achieve the objectives set for } \\
\text { them and respond to the needs } \\
\text { of students and society. These } \\
\text { reviews should lead to } \\
\text { continuous improvement of the } \\
\text { programme. Any action planned } \\
\text { or taken as a result should be } \\
\text { communicated to all those } \\
\text { concerned. } \\
1.10 \text { Cyclical external quality } \\
\text { assurance - Institutions should } \\
\text { undergo external quality } \\
\text { assurance in line }\end{array}$ & 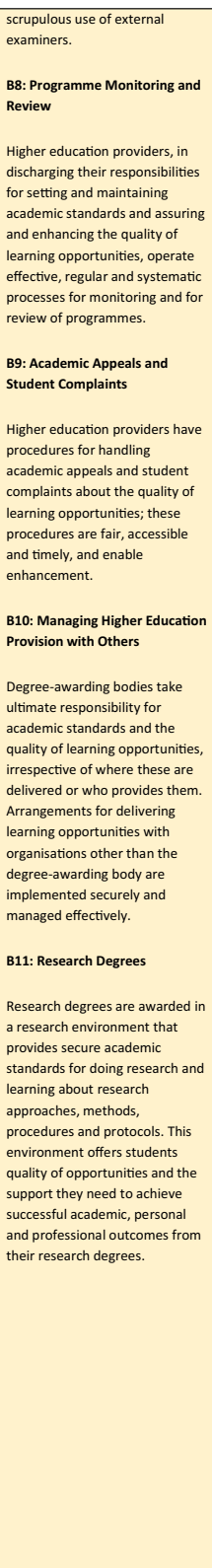 & 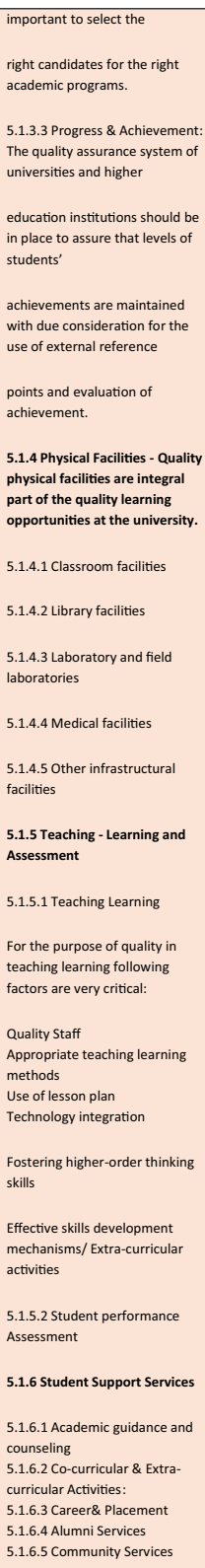 \\
\hline
\end{tabular}




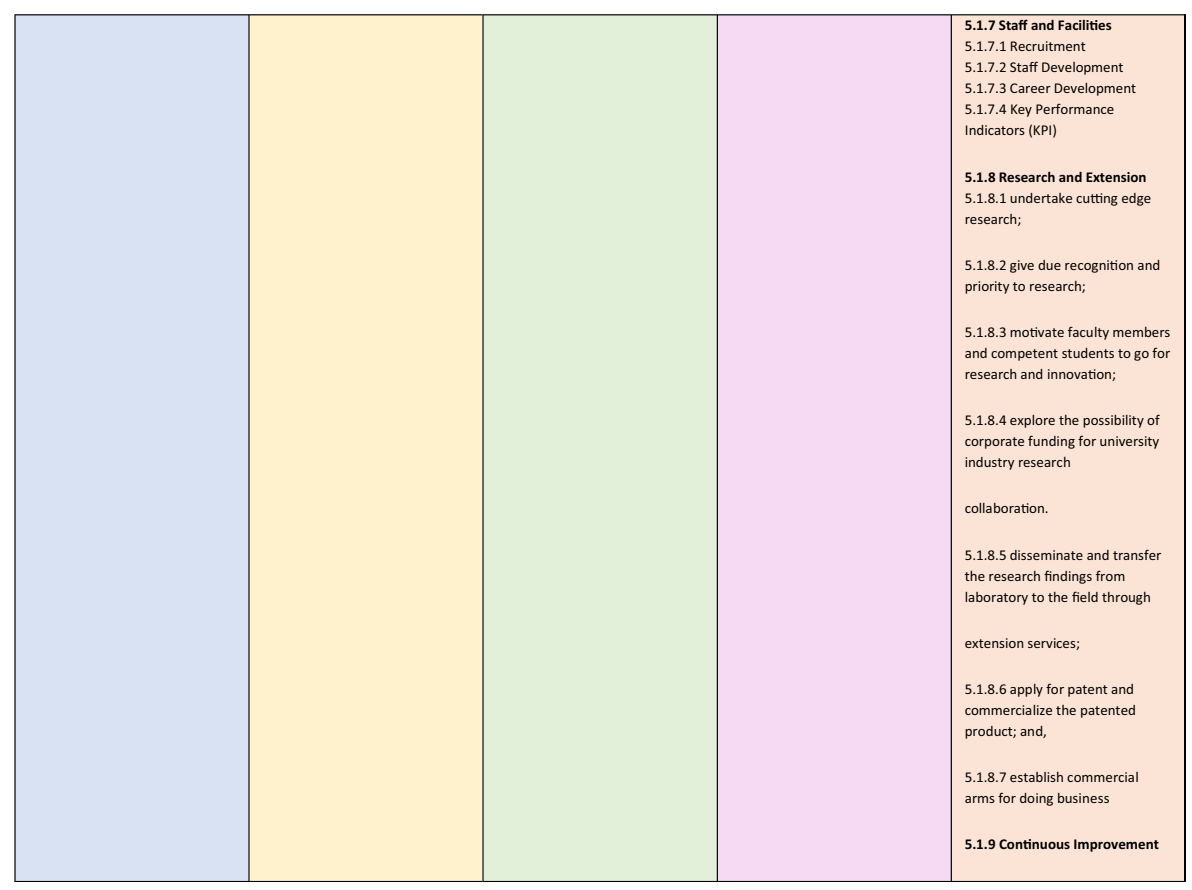

\section{Appendix II Interview Guide}

- What does quality culture mean to you?

- Does an institution need to have developed a quality culture prior to implementation of a process of quality assurance or does the quality assurance system help in the development of the culture with the institution?

- How well do you think the Quality Assurance Framework (QAF) have been successful in developing a culture of compliance?

- What do you think are the challenges in a quality assurance system that will instill quality culture at your institution?

- In your opinion what are the indicators for a successful implementation of quality culture at your institution?

- In your opinion, what can be done to support the development of a QC?

Open Access This article is licensed under a Creative Commons Attribution 4.0 International License, which permits use, sharing, adaptation, distribution and reproduction in any medium or format, as long as you give appropriate credit to the original author(s) and the source, provide a link to the Creative Commons licence, and indicate if changes were made. The images or other third party material in this article are included in the article's Creative Commons licence, unless indicated otherwise in a credit line to the material. If material is not included in the article's Creative Commons licence and your intended use is not permitted by statutory regulation or exceeds the permitted use, you will need to obtain permission directly from the copyright holder. To view a copy of this licence, visit http://creativecommons.org/licenses/by/4.0/. 


\section{References}

(BANBEIS) Bangladesh Bureau of Educational Information and Statistics. (2018). Bangladesh education statistics. Available from:. http://lib.banbeis.gov.bd/BANBEIS_PDF/Bangledesh\%20Education\%20 Statistics\%202018.pdf (Accessed from: August 25, 2018)

(ENQA) European Association for Quality Assurance in Higher Education. (2008). Quality procedures in the European Higher Education Area and beyond - second ENQA survey, Helsinki: ENQA. Available from http://www.enqa.eu/pubs.lasso. (Accessed: 25 May 2018).

(EUA) European University Association. (2006). Quality culture in European universities: a bottom-up approach. In Report on the Three Rounds of the Quality Culture Project 2002-2006. Brussels: EUA.

(EUA) European University Association. (2010). Trends 2010: A decade of change in European higher education, Sursock, A. and Smidt, H (Brussels, EUA). Available from: http:/www.eua.be/fileadmin/user_ upload/files/Publications/Trends_2010.pdf. (Accessed: 5 August 2018).

Institutional Quality Assurance Cell Operations Manual. (2014). Available from: http:/www.heqep-ugc.gov. bd/download_file/downloadfile_1409040439.pdf . (Accessed: 25 June 2018)

Abma, T. A., \& Widdershoven, G. A. M. (2008). Evaluation and/as social relation. Evaluation, 14(2), 209225. https://doi.org/10.1177/1356389007087540.

Adina-Petruța, P. (2014). Quality culture - a key issue for romanian higher education. Procedia - Social and Behavioral Sciences, 116, 3805-3810. https://doi.org/10.1016/j.sbspro.2014.01.845.

Ahmed, J. U. (2016). Massification to marketization of higher education: private university education in Bangladesh. Higher Education for the Future., 3(1), 76-92. https://doi.org/10.1177/2347631115610222.

Akareem, H. S., \& Hossain, S. S. (2012). Perception of education quality in private universities of Bangladesh: a study from students' perspective. Journal of Marketing for Higher Education, 22(1), 11-33. https://doi. org/10.1080/08841241.2012.705792.

Ansah, F. (2015). A strategic quality assurance framework in an African higher education context. Quality in Higher Education, 21(2), 132-150. https://doi.org/10.1080/13538322.2015.1084720.

Aviv, R. (2000). Educational performance of ALN via content analysis. Journal of Asynchronous Learning Network., 4(2), 53-72 http://citeseerx.ist.psu.edu/viewdoc/download?doi=10.1.1.131.7147\&rep=rep1\&type=pdf.

Barbulescu, A. (2015). Quality culture in the Romanian higher education. Procedia - Social and Behavioral Sciences, 191, 1923-1927. https://doi.org/10.1016/j.sbspro.2015.04.445.

Bendermacher, G. W. G., et al. (2017). Unravelling quality culture in higher education: a realist review. Higher Education, 73(1), 39-60. https://doi.org/10.1007/s10734-015-9979-2.

Berings, D., and Grieten, S. (2012). Dialectical reasoning around quality culture. Paper presented at the seventh European Quality Assurance Forum (EQAF) of the European University Association (EUA), Tallinn. Nov 22-24, 2012. https://eua.eu/downloads/publications/berings_grieten.pdf.

Bollaert, L. (2014). A manual for internal quality assurance in higher education with special focus on professional higher education. Brussels: European Association of Institutions in Higher Education https:/www.eurashe.eu/library/eurashe_sem_qa_141203-04_pres_bollaert_1-pdf/.

(BPMC) Bologna Process Ministerial Conference. (2003). Realizing the European Higher Education Area, Communiqué of the Conference of Ministers responsible for Higher Education. Available from: http://www.ehea.info/media.ehea.info/file/2003_Berlin/28/4/2003_Berlin_Communique_ English_577284.pdf. (Accessed: 5 September 2018).

Braun, V., \& Clarke, V. (2006). Using thematic analysis in psychology. Qualitative Research in Psychology, 3(2), 77-101. https://doi.org/10.1191/1478088706qp063oa.

British Council Report. (2012). The shape of things to come: higher education global trends and emerging opportunities to 2020. Available from: https://www.britishcouncil.org/sites/default/files/the_shape_of things_to_come_-_higher_education_global_trends_and_emerging_opportunities_to_2020.pdf. (Accessed: May 8, 2018).

Brookes, M., \& Becket, N. (2007). Quality management in higher education: a review of international issues and practice. International Journal of Quality Standards, 1(1), 85-121 https://www.scirp.org/(S(lz5 mqp453edsnp55rrgjct55))/reference/ReferencesPapers.aspx?ReferenceID=2038569.

Cameron, K. S., \& Freeman, S. J. (1991). Cultural congruence, strength, and type: eelationships to effectiveness. Research in organizational change and development, 5(1), 23-58.

Church, C. H. (1988). The qualities of validation. Studies in Higher Education, 13, 27-43. https://doi. org/10.1080/03075078812331377945.

Cohen, L., Manion, L., \& Morrison, K. (2000). Research methods in education (5th ed.). London: Routledge.

Conrad, K. J., Randolph, F. L., Kirby Jr., M. W., \& Bebout, R. R. (1999). Creating and using logic models. Alcoholism Treatment Quarterly, 17(1-2), 17-31. https://doi.org/10.1300/J020v17n01_02. 
Corbetta, P. (2003). Social research. London: SAGE Publications.

Council for Higher Education Accreditation (CHEA). (2014). International higher education and international quality standards. Policy Brief No. 3. Retrieved June 12, 2018 from: https://www.chea.org/userfiles/ Policy-Briefs/CIQG_Policy_Brief_Vol-3.pdf.

Crosby, P. B. (1986). Running things - the art of making things happen. Milwaukee: American Society for Quality Control.

Dale, B. G., Cooper, C. L., \& Wilkinson, A. (1997). Managing quality and human resources - a guide to continuous improvement. UK: Blackwell Publishers Ltd.

Deem, R., Mok, K. H., \& Lucas, L. (2008). Transforming higher education in whose image? Exploring the concept of the 'world-class' university in Europe and Asia. Higher Education Policy, 21(3), 83-97. https://doi.org/10.1057/palgrave.hep.8300179.

Dellana, S. A., \& Hauser, R. D. (1999). Towards defining quality culture. Engineering Management Journal., 11(2), 11-15. https://doi.org/10.1080/10429247.1999.11415022.

Ehsan, M. (2008). Higher education governance in Bangladesh: the public private dilemma (Dhaka, A H Development).

Elliott, J. (2005). Using narrative in social research: qualitative and quantitative approaches. London: Sage.

ENQA, ESU, EUA et al. (2014). Standards and guidelines for quality assurance in the European Higher Education Area, revised version, Endorsed by the Bologna Follow-Up Group in September 2014, Available from: https://revisionesg.files.wordpress.com/2014/10/esg-draftendoresed-by-bfug.pdf. (Accessed: 5 July 2018).

Ewell, P. (2010). Twenty years of quality assurance in higher education: what's happened and what's different? Quality in Higher Education, 16(2), 173-175. https://doi.org/10.1080/13538322.2010.485728.

Government of Bangladesh. (2010). National Education Policy. Ministry of Education. Available from: https://moedu.portal.gov.bd/sites/default/files/files/moedu.portal.gov.bd/page/ad5cfca5_9b1e_4c0c_a4eb_fb1 ded9e2fe5/National\%20Education\%20Policy-English\%20corrected\%20_2_.pdf. (Accessed: 25 April 2019).

Greere, A., \& Riley, C. (2014). Engagement, empowerment, ownership - how to nurture the quality culture in higher education. In D. Derricott, H. Kekalainen, et al. (Eds.), Working together to take quality forward, A selection of papers from the 8th European Quality Assurance Forum (pp. 38-43). Brussels: European University Association.

Gryna, F. M., Chua, R. C. H., \& DeFeo, J. A. (2007). Juran's quality planning and analysis for enterprise quality. New York: McGraw-Hill.

Hargreaves, T. (2011). Practice-ing behaviour change: applying social practice theory to pro-environmental behaviour change. Journal of Consumer Culture, 11(1), 79-99. https://doi.org/10.1177/1469540510390500.

Harvey, L. (2002) The End of Quality? Quality in Higher Education, 8(1). Available from: http://www. qualityresearchinternational.com/Harvey\%20papers/Harvey\%202002\%20Overview\%20of\%20the $\% 20$ End\%20of\%20Quality.pdf. (Accessed: 10 May 2019).

Harvey, L., \& Green, D. (1993). Defining quality. Assessment and Evaluation in Higher Education, 18(1), 934. https://doi.org/10.1080/0260293930180102.

Harvey, L., \& Stensaker, B. (2008). Quality culture: understandings, boundaries and linkages. European Journal of Education, 43(4), 427-442. https://doi.org/10.1111/j.1465-3435.2008.00367.x.

Hatch, M. J., and Cunliffe, A. L. (2006). Organization theory. Oxford: Oxford University Press.

Hays, S. (1994). Structure and agency and the sticky problem of culture. Sociological Theory, 12(1), 57-72 https://www.jstor.org/stable/202035.

Helitzer, D., et al. (2010). Evaluation for community-based programmes: the integration of logic models and factor analysis. Evaluation and Programme Planning, 33, 223-233. https://doi.org/10.1016/j.evalprogplan.2009.08.005.

Hildebrandt, S., Kkistensen, K., Kanji, G., \& Dahlgaard, J. J. (1991). Quality culture and TQM. Total Quality Management., 2(1), 1-15. https://doi.org/10.1080/09544129100000001.

Hopbach, A. (2011). External quality assurance at national level and its links to the European level. Paper presented at the Future of Higher Education - Bologna Process Researchers Conference (FOHE-BPRC), Bucharest, Romania.

Hou, A.Y. (2012). Mutual recognition of quality assurance decisions on higher education institutions in three regions: a lesson for Asia. Higher Education 64, 911-926. https://doi.org/10.1007/s10734-012-9536-1.

Hou, A., Chen, K., Hui-Jung, \& Morse, R. (2014). Transforming the quality assurance framework for Taiwanese higher education: a glonacal context. Policy and Society, 33(3), 275-285. https://oi. org/10.1016/j.polsoc.2014.09.001.

Huisman, J. (1995). Differentiation, Diversity and Dependency in Higher Education. Utrecht: Lemma. Available from: https:/www.academia.edu/280441/Differentiation_diversity_and_dependency_in_ higher_education_A_theoretical_and_empirical_analysis. (Accessed: 5 August 2019).

Islam, G. M. N. (2014). Journey towards QAA (Quality Assurance and Accreditation) mechanism to improve quality education of HELs (Higher Education Institutions) in Bangladesh - issues, challenges and 
prospects. MA dissertation, BRAC University. Available from: http://dspace.bracu.ac. bd/xmlui/händle/10361/4060. (Accessed: November 1, 2018).

Islam, G. M. N., Ali, M. I. and Islam, M. Z. (2017). Quality assurance and accreditation mechanisms of higher education institutions: policy issues and challenges in Bangladesh, European Journal of Education Studies, 3 (5). Available from: https://oapub.org/edu/index.php/ejes/article/view/658. (Accessed: November 1, 2018).

Jawad, S., Jamshaid, I., \& Wahab, F. (2015). Quality culture in higher education institutes: perspective of different stakeholders. VFAST Transaction on Education and Social Sciences, 6(2), 72-79. https://doi. org/10.21015/vtess.v6i2.309.

Jordan, G. B. (2010). A theory-based logic model for innovation policy and evaluation. Research Evaluation, 19, 263-273.

Kazdin, A. E. (1992). Research design in clinical psychology. Needham Heights: Allyn \& Bacon.

Kohoutek, J., Land, R. and Owen, C. (2013). Identifying barriers in promoting the European Standards and Guidelines for Quality Assurance at institutional level (IBAR), Final Synthesis Report. Available at: http://www.ibar-llp.eu/results/main-results/finalsynthesis-report.html. (Accessed: 6 July 2018).

Krouglov, A. (2017). Transforming higher education in Uzbekistan: from quality control to quality assurance culture. (Ed.) Shah, M \& Quyen, T.N. D. The rise of quality assurance in Asian higher education, Chandos Publishing, pg. 173-189.

Kunda, G. (1992). Engineering culture: control and commitment in a high tech corporation. Philadelphia, PA: Temple University Press.

Lamagna, C., Villanueva, C. C., \& Hassan, F. (2017). The effects of internal quality assurance on quality and employability: American International University - Bangladesh. UNESCO International Institute for Educational Planning.

Lanarès, J. (2009). Tracking the development of a quality culture. Is the discourse translated into action? Paper presented at the 4th European Quality Assurance Forum, 19-21 November, Copenhagen https://www.eurashe.eu/library/quality-he/Ia.1 - Lanares.pdf.

Land, R., \& Rattray, J. (2014). Policy drivers and barriers to implementation: contexts of practice. In H. Eggins (Ed.), Drivers and barriers to achieving quality in higher education (pp. 13-26). Rotterdam: Sense Publishers.

Lycke, L., \& Tano, I. (2017). Building quality culture in higher education. International Journal of Quality and Service Sciences, 9(3/4), 331-346. https://doi.org/10.1108/IJQSS-04-2017-0033.

Maringe, F. (2010). The meaning of globalization and internationalization in HE: findings from a World Survey. In F. Maringe \& N. Foskett (Eds.), Globalization and internationalization in higher education, theoretical, strategic, and management perspectives. London: Continuum.

Maykut, P., \& Morehouse, R. (1994). Beginning qualitative research: a philosophical and practical guide. London: Falmer Press.

McCawley, P. (2002). The logic model for program planning and evaluation. University of Idaho Extension. Available from: http://www.uiweb.uidaho.edu/extension/LogicModel.pdf. (Accessed: November 1, 2018).

McLaughlin, J. A., \& Jordan, G. B. (1999). Logic models: a tool for telling your program's performance story. Evaluation and Program Planning, 22, 65-72. https://oi.org/10.1016/S0149-7189(98)00042-1.

McNiff, J., \& Whitehead, J. (2002). Action research: principles and practice. London: Taylor and Francis.

Millar, A., Simeone, R. S., \& Carnevale, J. T. (2001). Logic models: a systems tool for performance management. Evaluation and Program Planning, 24, 73-81. https://doi.org/10.1016/S0149-7189(00)00048-3.

Newton, J. (2002). Views from below: academics coping with quality. Quality in Higher Education, 8(1), 3961. https://doi.org/10.1080/13538320220127434.

Newton, X. A., Poon, R. C., Nunes, N. L., \& Stone, E. M. (2013). Research in teacher education programs: logic model approach. Evaluation and Program Planning, 36, 88-96. https://doi.org/10.1016/j. evalprogplan.2012.08.001.

Ntim, S. (2014). Embedding quality culture in higher education in Ghana: quality control and assessment in emerging private universities. Higher Education, 68, 837-849 http://www.jstor.org/stable/43648758.

OECD and World Bank. (2007). Cross-border tertiary education: a way towards capacity development.

Parvin, A. (2019). Leadership and management in quality assurance: insights from the context of Khulna University, Bangladesh. Higher Education, 77, 739. https://doi.org/10.1007/s10734-018-0299-1.

Patton, M. Q. (1990). Qualitative evaluation and research methods. Newbury Park: Sage.

Pawson, R. \& Tilley, N. (1997). Realistic Evaluation. London: Sage.

Poole, D. L., Davis, J. K., Reisman, J., \& Nelson, J. E. (2001). Improving the quality of outcome evaluation plans. Nonprofit Management and Leadership, 11, 405-421. https://doi.org/10.1002/nml.11402.

Price, R. M., Alkema, G. E., \& Frank, J. C. (2009). California Geriatric Education Center logic model: an evaluation and communication tool. Gerontology \& Geriatrics Education, 30(4), 317-331. https://doi. org/10.1080/02701960903347691. 
Quyen T. N. D., Huong T. P. and Kim D. N. (2017). Quality assurance in the Vietnamese higher education: a top-down approach and compliance-driven QA. in Shah, M \& Quyen, T.N. D. (Ed.) The rise of quality assurance in Asian higher education, Chandos Publishing, pg. 191-207.

Ramirez, G. B., \& Haque, H. M. J. (2016). Addressing quality challenges in the private university sector in Bangladesh: from policy formulation to institutional implementation. Quality in Higher Education, 22(2), 139-151. https://doi.org/10.1080/13538322.2016.1198177.

Reckwitz, A. (2002). Toward a theory of social practices: a development in culturalist theorizing. European Journal of Social Theory, 5(2), 243-263. https://doi.org/10.1177/13684310222225432.

Salmi, J. (2008). The growing accountability agenda: Progress or mixed blessing? IMHE/OECD Annual Conference "Outcomes of higher education: Quality relevance and impact" September 8-10, 2008, Paris, France. Available from: http://www.oecd.org/dataoecd/3/30/41218034.pdfhttp://www.oecd. org/dataoecd/3/30/41218034.pdf. (Accessed: 25 May 2018).

Sargeant, J. (2012). Qualitative research part II: participants, analysis, and quality assurance. Journal of Graduate Medical Education, 4(1), 1-3. https://doi.org/10.4300/JGME-D-11-00307.1.

Sattler, C., \& Sonntag, K. (2018). Quality cultures in higher education institutions - development of the Quality Culture Inventory. In P. Meusburger, M. Heffernan, \& L. Suarsana (Eds.), Geographies of the university (pp. 313-327). Cham: Springer International Publishing.

Saunders, M. (2011). Capturing effects of interventions, policies and programmes in the European context: a social practice perspective. Evaluation., 17(1), 89-102. https://doi.org/10.1177/1356389010394480.

Saunders, M., Trowler, P., \& Bamber, V. (2011). Reconceptualizing evaluation in higher education: the practice turn. Maidenhead: Open University Press / SRHE.

Savaya, R., \& Waysman, M. (2005). The logic model. Administration in Social Work, 29(2), 85-103. https://doi.org/10.1300/J147v29n02_06.

Schein, E. H. (1996). Culture: the missing conception in organization studies. Administrative Science Quarterly, 41, 229-240. https://doi.org/10.2307/2393715.

Schein, E. H. (2004). Organizational culture and leadership (3rd ed.). San Francisco: Jossey-Bass.

Scott, T. (2003). The quantitative measurement of organizational culture in health care: a review of the available instruments. Health Service Research, pp., 1-37. https://doi.org/10.1111/1475-6773.00154.

Seraph, J., \& Sebastian, R. (1993). Developing a quality culture. Quality Progress., 26(9), 73-78.

Sursock, A. (2012). Quality assurance and the European Transformational Agenda. In A. Curaj et al. (Eds.), European higher education at the crossroads: between the Bologna Process and national reforms. Dordrecht: Springer.

TEQSA. (2015). Higher Education Standards Framework (Threshold Standards) 2015. Retrieved June 21, 2018 from: https://www.teqsa.gov.au/contextual-overview-hes-framework-2015.

Tierney, W. G. (1988). Organizational culture in higher education: defining the essentials. The Journal of Higher Education, 59(1), 2-21. https://doi.org/10.1080/00221546.1988.11778301.

Trow M. (2007) Reflections on the transition from elite to mass to universal access: forms and phases of higher education in modern societies since WWII. In Forest J. J. F., Altbach P. G. (eds) International handbook of higher education. Springer International Handbooks of Education, vol 18. Springer, Dordrecht.

UNESCO. (2005). Guidelines for quality provision in cross-border education. Paris: UNESCO Publishing.

Varonism, E. M. (2014). Most courses are not born digital: an overview of the Quality Matters peer review process for online course design. Campus-Wide Information Systems, 31(4), 217-229. https:/doi. org/10.1108/CWIS-09-2013-0053.

Warde, A. (2005). Consumption and theories of practice. Journal of Consumer Culture, 5, 131-153. https://doi.org/10.1177/1469540505053090.

Westbrook, J. D. (1993). Organizational culture and its relationship to TQM. Industrial Management., 35(1), 1-3.

Wihlborg, M., \& Robson, S. (2018). Internationalisation of higher education: drivers, rationales, priorities, values and impacts. European Journal of Higher Education, 8(1), 8-18. https://doi.org/10.1080 /21568235.2017.1376696.

World Bank Project Aide Memoire. (2017). Bangladesh Higher Education Quality Enhancement Project (HEQEP) 15th Implementation Support Mission. Retrieved 29 July, 2018. http://pubdocs.worldbank. org/en/721581490608702587/AM-Mar-2017.pdf.

Yang, J.-T. (2007). Knowledge sharing: investigating appropriate leadership roles and collaborative culture. Tourism Management, 28, 530-543. https://doi.org/10.1016/j.tourman.2006.08.006.

Yin, R. K. (2014). Case study research design and methods (5th ed.). Thousand Oaks: Sage.

Yorke, M. (2000). Developing a quality culture in higher education. Tertiary Education and Management, 6(1), 19-36. https://doi.org/10.1080/13583883.2000.9967008.

Publisher's note Springer Nature remains neutral with regard to jurisdictional claims in published maps and institutional affiliations. 